\title{
Denizli'deki dağ göllerinin Oligochaeta (Annelida) faunası üzerine gözlemler
}

\section{Observations on the Oligochaeta (Annelida) fauna of the mountain lakes in Denizli (Turkey)}

\section{Seray Yıldız • M. Ruşen Ustaoğlu}

Ege Üniversitesi, Su Ürünleri Fakültesi, Su Ürünleri Temel Bilimler Bölümü, 35100, Bornova, İzmir ${ }^{*}$ Corresponding author: seray.yildiz@ege.edu.tr

How to cite this paper:

Yıldız, S. \& Ustaoğlu, M.R. (2016). Observations on the Oligochaeta (Annelida) fauna of the mountain lakes in Denizli (Turkey) (in Turkish with English abstract) Ege Journal of Fisheries and Aquatic Sciences, 33(2): 89-96. doi: 10.12714/egejfas.2016.33.2.01

\begin{abstract}
Öz: Sandıras ve Çiçekbaba Dağları zirvelerinde yer alan Kartal Gölü ve zirveye yakın Gökçeova Göleti, Honaz ilçesi yakınlarındaki Saklıgöl ve Bozkurt ilçesi yakınlarındaki Karagöl'ün Oligochaeta (Annelida) faunasını belirlemek üzere 2009, 2010 ve 2011 yılları Haziran, Temmuz ve Ağustos aylarında 4 örnekleme çalışması yapılmıştır. Kalitatif değerlendirmeler sonucunda, örnekleme yapılan göllerin tümünden değişen sayılarda oligoket türleri tespit edilmiş, 3 ordo içeriğinde 3 familyaya ait bireyler tanımlanmıştır. 17'si Naididae (14'ü Tubificinae altfamilyası, 3'ü Naidinae altfamilyası), 1'i Lumbriculidae ve 3'ü Enchytraeidae olmak üzere toplam 21 Oligochaeta taksonu saptanmıştır.
\end{abstract}

Anahtar kelimeler: Alpin, göl, gölet, Denizli, Oligochaeta, prealpin

Abstract: : The Oligochaeta (Annelida) community compositions of high elevation lakes Kartal and Gökçeova Pond located on Sandıras and Çiçekbaba mountains (Denizli, Turkey) and Lake Saklıgöl (Honaz), Lake Karagöl (Bozkurt) were studied. During the present study, four expeditions were conducted in June, July and August of 2009, 2010, and 2011 in order to collect the oligochaetes from these lakes. As a result of qualitative assessments, oligochaete species have been identified in varying numbers from all of the lakes sampled, 3 individuals belonging to 3 families have been identified. A total of 21 taxa were determined, 17 taxa from Naididae (14 to subfamily Tubificina, 3 to subfamily Naidinae), 1 taxon from Lumbriculida and 3 taxa from Enchytraeidae.

Keywords: Alpine, Denizli, lake, Oligochaeta, pond, prealpine.

\section{GiRiş}

Yüksek rakımlı dağ göllerinde bulunan makroomurgasızlar benzersiz ve çoğunlukla ekstrem çevresel koşullara adaptasyon sağlamışlardır (Mani, 1968). Genelde, yüksek rakımlı yerler tipik olarak ovalarda bulunan bölgelerden daha soğuktur ve buzsuz ve karsız geçirdikleri dönem daha sınırlıdır. Makroomurgasızların gelişme periyotları kısıtı ve besin kaynaklarının eldesi de azaltılmış ve düzensizdir. Buna ek olarak, yüksek dağlardaki makroomurgasızların dağılımı, fizyografik bariyerler ve uygun habitat eldesinin azlığı yüzünden zorlaşmış ve karmaşık bir hal almıştır (Mani, 1968).

Araştırmamızın ana konusu olan ve bentik bölgede yayılış gösteren Oligochaeta türleri genelde serbest olarak su tabanında yaşarlar ve sucul ekosistemlerdeki besin zincirinin önemli halkalarından birini oluşturan makroomurgasızlardandır. Çünkü çok sayıdaki araştırmalar bu canlıların balıklar ve bazı kabuklular tarafından sevilerek tüketildiklerini, başta protein olmak üzere, önemli besin unsurlarını içerdiklerini ortaya koymuştur (Thienemann, 1954; Brinkhurst, 1974; Fittkau ve Reiss, 1986). Bunların dışında, bazı araştırıcılar da bu canlıları değişik özelliklerine göre biyoindikatör olarak kullanmışlardır (Şahin, 1991). Biyoindikatör özelliklerinden dolayı diğer omurgasız gruplarıyla birlikte (özellikle Chironomidae, Gastropoda) kullanıldıkları takdirde, çalışılan tatlı su ekosistemi hakkında kimyasal yöntemlere göre çok daha ucuza gelen doğru sonuçlar verebilmektedirler (Yıldız ve Balık, 2005).

Ülkemizde yüksek dağlar üzerinde lokalize olmuş buzul ve diğer farklı orijinli göllerimizin limnolojisi üzerine çalışmalar günümüzde giderek artmaktadır (Balık vd., 2003; Ustaoğlu vd., 2004; Taşdemir vd., 2004 a, b; Ustaoğlu vd., 2005; Yıldız vd., 2005; Yıldız vd., 2007a; Yıldız vd., 2008; Ustaoğlu vd., 2008; Yıldız vd., 2009; Topkara vd., 2009; Taşdemir vd., 2010; Yıldız vd., 2010a; Yıldız vd., 2012; Sarı vd., 2015; Topkara ve Ustaoğlu, 2015). 
Yapılan bu çalışmada Sandıras Dağı zirvesinde yer alan Kartal Gölü ve zirveye yakın Gökçeova Göleti, Honaz ilçesi yakınlarındaki Saklıgöl ve Bozkurt ilçesi yakınlarındaki Karagöl'ün ekolojik özellikleri ile biyolojik (fauna) çeşitliliklerinin saptanması düşünülmüştür. Oligochaeta faunasının belirlenmesi ise bu geniş kapsamlı çalışmanın bir parçasıdır.

Araştırmaya konu olan bölge üzerindeki bu tip su yapılarında henüz yapılmış çalışmalar bulunmamaktadır. Bu açıdan taksonomik olarak değerlendirebilecek bu çalışma ilk olma niteliği taşımaktadır ve tespit edilen türler de bu bölgedeki göller için yeni kayıt niteliğindedir.

\section{MATERYAL VE METOT}

Sandıras ve Çiçekbaba Dağları zirvelerinde yer alan Kartal Gölü ve zirveye yakın Gökçeova Göleti, Honaz ilçesi yakınlarındaki Saklıgöl ve Bozkurt ilçesi yakınlarındaki Karagöl'ün Oligochaeta (Annelida) faunasını belirlemek üzere 2009-2011 yılları yaz mevsimlerinde örnekleme çalışmaları yapılmıştır (Şekil 1, Tablo 1).

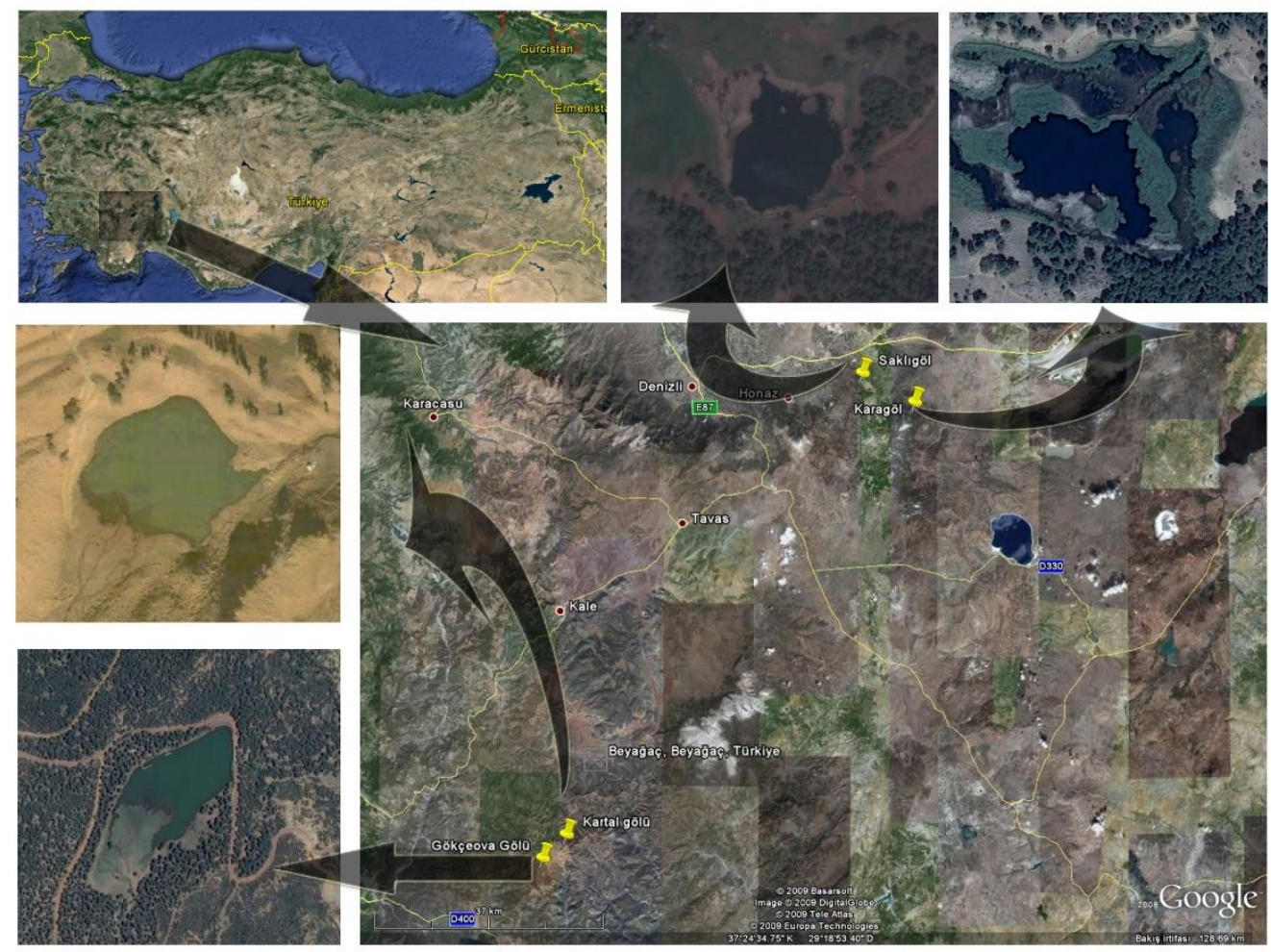

Şekil 1. Çalışılan bölgenin genel görünüşü ve araştırma yapılan göller

Figure 1. General views of the studied localities and lakes surveyed

Tablo 1. Araştırma yapılan istasyonlar ve genel özellikleri

Table 1. Studied localities and their general features

\begin{tabular}{clcccc}
\hline İst. & Lokalite & Koordinat & Rakım (m) & Derinlik(cm) & Makrofit \\
\hline 1 & Kartal Gölü & $37^{\circ} 05^{\prime} \mathrm{K}-28^{\circ} 51^{\prime} \mathrm{D}$ & 1885 & 120 & - \\
2 & Gökçeova Göleti & $37^{\circ} 03^{\prime} \mathrm{K}-28^{\circ} 48^{\prime} \mathrm{D}$ & 1755 & 480 & - \\
3 & Karagöl & $37^{\circ} 44^{\prime} \mathrm{K}-29^{\circ} 29^{\prime} \mathrm{D}$ & 1248 & 170 & + \\
4 & Saklıgöl & $37^{\circ} 46^{\prime} \mathrm{K}-29^{\circ} 23^{\prime} \mathrm{D}$ & 953 & 800 & + \\
\hline
\end{tabular}

Göl suyunun sıcaklık ölçümleri $0,1^{\circ} \mathrm{C}$ hassasiyetli termometre, pH ölçümleri WTW 330 model pH metre, iletkenlik ölçümleri YSI 30 model SCT-metre ve çözünmüş oksijen WTW 330 model oksijen-metre kullanılarak yerinde ölçüm yapıımıştır. 
Oligoket örnekleri $180 \mu \mathrm{m}$ göz açıklığındaki el kepçeleri ve Ekman-Birge Grab ile alınan çamur örneklerinin $500 \mu \mathrm{m}$ göz açıklığındaki elekten geçirilmesiyle toplanmıştır.

Arazide \% 4'lük formolde fikse edilen bentik örnekler laboratuarda bol su ile yıkanıp ayıklandıktan sonra \% 70'lik alkolde saklanmıştır. Ayıklanan örneklerin CMCP-10 ile preparasyonu yapıldıktan sonra stereomikroskop ve binoküler mikroskop kullanılarak tür tayinleri gerçekleştirilmiştir.
Örneklerin taksonomik incelenmesinde, Brinkhurst ve Jamieson (1971), Nielsen ve Christensen (1959), Timm (2009), Timm ve Veldhuijzen Van Zanten (2002)'in yayınlarından yararlanılmıştır.

\section{BULGULAR}

Çalışmada göllerin sularında ölçülen fiziko-kimyasal parametreler Tablo 2'de verilmiştir.

Tablo 2. İstasyonlarda ölçülen fiziko-kimyasal parametreler

Table 2. Physicochemical parameters measured at stations

\begin{tabular}{|c|c|c|c|c|c|}
\hline \multirow{2}{*}{ Göller } & \multirow{2}{*}{ Parametreler } & \multicolumn{2}{|c|}{2009} & \multirow{2}{*}{$\begin{array}{c}2010 \\
\text { Temmuz }\end{array}$} & \multirow{2}{*}{$\begin{array}{c}2011 \\
\text { Temmuz }\end{array}$} \\
\hline & & Haziran & Ağustos & & \\
\hline \multirow{5}{*}{ 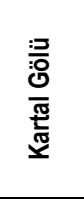 } & Sıcaklık $\left({ }^{\circ} \mathrm{C}\right)$ & 18 & 21.5 & 23.7 & 17.9 \\
\hline & $\mathrm{pH}$ & 8.45 & 9.06 & 8.58 & 8.25 \\
\hline & Çözünmüş Oksijen (mg/l) & 8.5 & 8.6 & 8.6 & 6.0 \\
\hline & Tuzluluk $(\% \circ \mathrm{S})$ & 0 & 0.1 & 0.1 & 0.1 \\
\hline & Illetkenlik $\left(\mu \mathrm{S}_{25^{\circ} \mathrm{C}} \mathrm{C}\right.$ & 84 & 108.5 & 102 & 100 \\
\hline \multirow{5}{*}{ 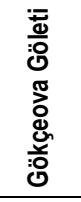 } & Sıcaklık ${ }^{\circ} \mathrm{C}$ & 19 & 20.5 & 23.3 & 25.1 \\
\hline & $\mathrm{pH}$ & 7.99 & 8,49 & 6.63 & 8.51 \\
\hline & Çözünmüş Oksijen (mg/l) & 7.2 & 6.7 & 5.7 & 4.9 \\
\hline & Tuzluluk (\%o S) & 0.1 & 0.1 & 0.1 & 0.1 \\
\hline & İletkenlik $\left(\mu S_{25^{\circ} \mathrm{C}}\right)$ & 211 & 249 & 229 & 249 \\
\hline \multirow{5}{*}{ 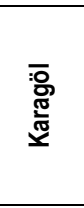 } & Sıcaklık ${ }^{\circ} \mathrm{C}$ & 25.6 & 24 & 25.9 & ${ }^{*}$ \\
\hline & $\mathrm{pH}$ & 7.89 & 8.05 & 8.02 & * \\
\hline & Çözünmüş Oksijen (mg/l) & 3.3 & 5.6 & 4.8 & * \\
\hline & Tuzluluk (\%o S) & 0.4 & 0.4 & 0.4 & * \\
\hline & İletkenlik $\left(\mu S_{25^{\circ} \mathrm{C}}\right)$ & 723 & 792 & 748 & * \\
\hline \multirow{5}{*}{$\begin{array}{l}\overline{0} \\
\text { 总 } \\
\text { 心 }\end{array}$} & Sıcaklık ( $\left.{ }^{\circ} \mathrm{C}\right)$ & $22.5^{\circ} \mathrm{C}$ & $23^{\circ} \mathrm{C}$ & $25.1^{\circ} \mathrm{C}$ & 27.5 \\
\hline & $\mathrm{pH}$ & 8.25 & 8.40 & 8.42 & 8.34 \\
\hline & Çözünmüş Oksijen (mg/l) & 5.2 & 5.7 & 5.5 & 4.3 \\
\hline & Tuzluluk (\%o S) & 0.5 & 0.5 & 0.5 & 0.5 \\
\hline & İletkenlik $\left(\mu S_{25^{\circ} \mathrm{C}}\right)$ & 960 & 1039 & 968 & 1038 \\
\hline
\end{tabular}

*Yol çalışması yüzünden göle ulaşılamadı.

Çalışma sonucunda, örnekleme yapılan istasyonların tümünden değişen sayılarda (Kartal Gölü'nde m²' de 402 birey, Gökçeova Göleti'nde m²' de 94 birey, Karagöl'de m²' de 40 birey) oligoket türleri tespit edilmiş, 3 ordo dahilinde 3 familyaya ait bireyler tanımlanmıştır. Bunlar; 17'si Naididae, (14'ü Tubificinae altfamilyası, 3'ü Naidinae altfamilyası), 1'i Lumbriculidae, 3'ü Enchytraeidae olmak üzere toplam 21 Oligochaeta taksonudur. Tespit edilen türlerin sistematik olarak dağılımı aşağıda verildiği gibidir.

Phylum: Annelida

Classis: Clitellata

Subclassis: Oligochaeta

Ordo: Tubificida

Familya: Naididae

Altfamilya: Naidinae

Nais elinguis Müller, 1774
Pristinella osborni (Walton, 1906)

Dero digitata (Müller, 1773)

Altfamilya: Tubificinae

Limnodrilus hoffmeisteri (Claparede, 1862)

Limnodrilus udekemianus (Claparede, 1862)

Limnodrilus profundicola (Verrill, 1871)

Tubifex tubifex (Müller,1774)

Tubifex tubifex $f$. bergi (Müller,1774)

Tubifex blanchardi (Vejdovsky, 1891)

Tubifex nerthus (Michaelsen, 1908)

Ilyodrilus templetoni (Southern, 1909)

Aulodrilus pluriseta (Piguet, 1906)

Aulodrilus pigueti (Kowalewski, 1914)

Potamothrix hammoniensis (Michaelsen, 1901)

Psammoryctides deserticola (Grimm, 1877)

Quistadrilus multisetosus (Smith, 1900)

Spirosperma nikolskyi (Lastockin and Sokolskaya, 1953) 
Ordo: Lumbriculida

Familya: Lumbriculidae

Lumbriculus variegatus (Müller, 1774)

Ordo: Enchytraeida

Familya: Enchytraeidae

Cognettia glandulosa (Michaelsen,1889)

Cognettia sphagnetorum (Vejdovsky, 1878)
Fridericia sp.

Tespit edilen Oligoket türlerinin çalışılan göllere göre dağılımları Tablo 3'te verilmiştir. Bu tablo dikkate alındığında, en fazla takson Kartal Gölü'nde (17 takson) tespit edilmiş, bunu 10 takson ile Gökçeova Göleti izlemektedir. Çalışma boyunca en bol bulunan türler Tubificinae altfamilyasından Limnodrilus hoffmeisteri ve Tubifex tubifex türleridir.

Tablo 3. Tespit edilen türlerin istasyonlara göre dağılımı (P: Profundal, L: Littoral)

Table 3. The distribution of species determined according to stations (P: Profundal, L: Littoral)

\begin{tabular}{|c|c|c|c|c|c|c|c|c|}
\hline \multirow[t]{2}{*}{ Taksonlar } & \multicolumn{2}{|c|}{ Kartal Gölü } & \multicolumn{2}{|c|}{ Gökçeova Göleti } & \multirow{2}{*}{$\begin{array}{c}\text { Saklıgöl } \\
\text { P }\end{array}$} & \multicolumn{3}{|c|}{ Karagöl } \\
\hline & $\mathbf{P}$ & $\mathbf{L}$ & $\mathbf{P}$ & $\mathbf{L}$ & & $\mathbf{L}$ & $\mathbf{P}$ & L \\
\hline Nais elinguis & - & + & - & - & - & - & - & - \\
\hline Pristinella osborni & - & + & - & - & - & - & - & - \\
\hline Dero digitata & - & + & + & - & - & - & - & - \\
\hline Limnodrilus hoffmeisteri & + & + & + & - & - & - & - & - \\
\hline Limnodrilus udekemianus & - & + & - & - & - & - & - & - \\
\hline Limnodrilus profundicola & - & + & - & - & - & - & - & - \\
\hline Tubifex tubifex & + & + & + & + & - & - & - & - \\
\hline Tubifex tubifex $f$. bergi & + & - & - & - & - & - & - & - \\
\hline Tubifex blanchardi & - & - & - & - & - & - & - & - \\
\hline Tubifex nerthus & - & + & - & - & - & - & + & - \\
\hline Ilyodrilus templetoni & - & + & - & - & - & - & - & - \\
\hline Aulodrilus pluriseta & + & + & - & - & - & - & - & - \\
\hline Aulodrilus piqueti & - & + & - & - & - & - & - & - \\
\hline Potamothrix hammoniensis & + & - & - & + & - & - & - & - \\
\hline Psammoryctides deserticola & - & - & - & + & - & - & - & - \\
\hline Quistadrilus multisetosus & - & - & - & + & - & - & - & - \\
\hline Spirosperma nikolskyi & - & + & + & - & - & - & - & - \\
\hline Lumbriculus variegatus & - & + & + & - & - & - & - & - \\
\hline Cognettia glandulosa & - & + & + & - & - & - & - & - \\
\hline Cognettia sphagnetorum & - & + & - & - & - & - & - & - \\
\hline Fridericha sp. & - & - & + & - & - & - & - & - \\
\hline
\end{tabular}

\section{TARTIŞMA VE SONUÇ}

Çalışmada en fazla taksonun tespit edildiği Kartal Gölü, Denizli ili, Beyağaç ilçesinin güneyindeki Çiçekbaba Dağı'nın zirvesinin kuzeye bakan yamacında yer alır. Denizden yüksekliği 1903 metredir. Buzul vadisinde oluşmuş bir moren seddi gölü olan Kartal Gölü ile çevresinde karaçamın saf meşcere oluşturması ve aralarında anıt ağaç özelliği gösteren bireylerin bulunması nedeniyle bu yörenin özelliklerinin korunarak bilim ve eğitim çalışmalarının hizmetine sunmak, doğal özelliği bozulmadan korunmasının sağlanmasının yanı sıra, bu alanlarda günümüz insanının ve gelecek nesillerin faydalanmasının temini amacı ile yörenin 1309 ha kısmı Orman Bakanlığı Milli Parklar ve Yaban Hayvanı Koruma Genel 
Müdürlüğü tarafından Tabiatı Koruma Alanı olarak ilan edilmiştir. Türkiye'nin en yaşlı Karaçam ormanı buradadır. Kartal Gölü ve "Anıt Orman" civarı, bitki florası bakımından çok zengindir. Doğa bilimcileri için ilgi odağıdır. Burada tespit edilen türlerin çoğu göle giren ve çıkan sulardan elde edilmiştir.

Gökçeova Göleti, Sandıras'ın zirvesine doğru tırmanırken, Gökçeova mevkii pınarlarının bulunduğu Dikenli Oluk civarında, "Altın Sivri" tepesi eteğinde yer alan kaynayan sulardan oluşan ve akış yönü kapatılarak oluşan yapay bir gölettir. Görevlilerin beklediği gölet, aynı zamanda orman yangını suyu olarak kullanılmak üzere korunmaktadır.

Denizli kent merkezine 55 kilometre uzaklıkta bulunan Çambaşı Mevkii'nde irili ufaklı birçok göl ve gölet bulunmaktadır. Bu göllerin en büyükleri olan Karagöl, Çambaşı Köyü'nün yaslandığı dağın zirvesine yakın bir konumda bulunur ve bu göle köyün içinden geçilerek ulaşılır. Çambaşı Köyü'nün güneybatısında bulunan geniş bir ormanlık alanda yer alan bu gölün çevresinde çeşitli su kaynakları da bulunur ve göl daha çok bu kaynaklardan beslenir. Uzun yıllar önce 3-4 küçük gölden meydana gelen, zaman içinde biraz daha küçülerek tek bir göl haline gelen Karagöl'ün yüzölçümü 1 kilometre, denizden yüksekliği ise 1250 m'dir. Göl, Denizli'nin yüksek kesimlerindeki pek çok göl gibi krater gölüdür ve pek çok krater gölünde olduğu gibi Karagöl'ün de tabanı çamurdur. Bu nedenle göl yüzeyinin önemli bir kısmı sazlık bitki örtüsü ile kaplanmıştır. Bahar aylarında canlanarak göle yemyeşil bir görünüm kazandıran bu sazlıklar, yaz aylarından itibaren kurur ve sarıya döner. Bu dönemden itibaren göle koyu sarı ve koyu mavi renkler hakim olur (Genç, 2014).

Su kaynağının bolluğu ve bozulmamış doğal dokusu sayesinde oldukça zengin bir flora ve faunaya sahip gölün etrafında dolaşırken, karaçam başta olmak üzere çeşitli iğne yapraklı ağaçlar, çalılar ve farklı otsu bitkilerle karşılaşmak mümkündür. Ayrıca, çeşitli balık ve kurbağa türleri ile ilginç böcek türleri de Karagöl'ün doğal yaşam alanında kendin göstermektedir (Genç, 2014).

Honaz ilçesinde, Honaz Dağı Milli Parkı (2571 m yüksekliğ ile Ege Bölgesi'nin en yüksek dağı olma özelliğine sahip olan Honaz Dağı, 21 Nisan 1995 tarihli Resmi Gazete'de yayınlanan 95 / 6717 sayılı Bakanlar Kurulu kararı ile Milli Park ilan edildi) sınırları içinde yer alan Saklıgöl ise herhangi bir akarsuyla beslenmemekte, suları dibinden kaynamaktadır. 1080 metre yükseklikteki Saklıgöl'ün çapı 300 metreyi geçmemektedir. Suyunun berrak ve temiz olmasının sebebi ise dibinden kaynamasıdır. Gölde sazlıklardan oluşan 7 tonluk yüzen bir ada mevcuttur. Ada rüzgârın etkisiyle zaman zaman yer değiştirmektedir (Dağdelen, 2013).

Çalışmada dominant olarak tespit edilen Naididae familyasına dahil Tubificinae altfamilyası, günümüzde her yerde dağılım göstermesine rağmen aslında orijini kuzey ılıman zondur (Timm, 1980).
Çalışmada dominant tür olan Tubifex tubifex, tatlı su formudur. Çok farklı ortamlarda bulunur, özellikle organik madde yönünden zengin habitatlara karşı oldukça toleranslıdır. Akarsu, kaynak ve havuzlarda bulunan en yaygın türlerden birisidir. Göllerde, özellikle litoralde, daha az sıklıkta görülür. Göllerin kirlenmiş kısımlarında ya da hızlı ötrofikasyonun olduğu ve bentik yaşamın bozguna uğradığı alanlarda çok bulunur. Kuzey Avrupa göllerinin profundalında çok geniş yayılım gösterir (Timm ve Veldhuijzen Van Zanten, 2002).

Yüksek rakımlı dağ gölleri ve buzul gölleri faunal kompozisyonları açısından nadir bulunan türleri içerirler ve oldukça izole çevrelerden oluşmuşlardır. Bu türlü su ortamlarına adapte olan canlılar bu bakımdan geniş toleranslara sahiptirler (Dumnicka ve Galas, 2002). Örneğin bu çalışmada dominant olarak rastladığımı $T$. tubifex kozmopolit ve $P$. hammoniensis ise çok geniş dağılıma sahip olan türlerdendir. T. tubifex, oldukça pollusyonlu habitatların bir göstergeci olarak bilinse de, oligotrofik alpin göllerde de bulunur. Bu tư̈ün ùlkemizdeki diğer dağ göllerinde bulunduğuna dair bir kaç çalışma mevcuttur (Geldiay ve Tareen, 1972; Ustaoğlu, 1980; Taşdemir vd., 2004a; Yıldız vd., 2007a; Ustaoğlu vd., 2008; Yıldız vd., 2009; Yıldız vd., 2010a; Yıldız vd., 2012; Yıldız vd., 2015). Toros Dağları üzerinde hemen hemen aynı rakımlarda bulunan yüksek bir dağ gölü olan Eğrigöl'de yapılan bir çalışmada da yine $T$. tubifex, $T$. nerthus ve $P$. hammoniensis tespit edilmiştir (Yıldız vd., 2005).

Diğer bir dominant tür olan Limnodrilus hoffmeisteri, kozmopolittir; birçok habitatta, özellikle kirli bölgelerde, en yaygın olan tubificidtir. Tatlı suların dip kısımlarında bulunur (Timm ve Veldhuijzen Van Zanten, 2002). Yaşam tarzı Tubifex'e benzer. Yaygın bir türdür. Özellikle kirlenmiş bölgelerdeki birçok habitatta en yaygın olan tubificidtir. Tatlı suların sedimentlerinin biyoturbasyonunda önemlidir. Hem lotik hem de lentik sulardan toplanırlar. Belki de, en temiz ortamlardan (pristine) yüksek derecede organik madde bakımından zengin bölgelere kadar yayılım gösteren en yaygın türdür. Özellikle kirli ve zengin ortamların karakteristiğidir. Göllerde sublittoral ve profundal zonun üst kısımlarındaki sedimentlerde bulunur. Ötrofik şartların indikatörüdür. Ayrıca kaynaklarda ve körfezlerin tatlısu kısımlarında da bulunur (Timm, 1970). Yaygın bir türdür. T. tubifex türü gibi yetiştiriciliği yapılabilen ekonomik bir türdür. Her zaman her yerde bulunan, organik materyal ve kirlenmenin bol olduğu sedimentlerde predominanttır (Marchese, 1987). Belirgin şekilde daha sıcak suları tercih eder. Düşük nitrat içerikli derelerde ve yüksek amonyak içerikli nehirlerde bulunur (Timm vd., 2001). Bu türün Türkiye'deki dağılımı $T$. tubifex türüyle benzerlik göstermektedir.

Tubifex nerthus türünün dağılımı Avrupa olarak verilmiştir. Tatlı acı sularda (Timm ve Veldhuijzen Van Zanten, 2002) ve genellikle nehirlerin gel-git alanlarındaki tatlı su bölümlerinde bulunur (Yıldız ve Balık, 2005). Bu tür Türkiye'de yüksek dağ göllerinin bulunduğu Batı Karadeniz Bölgesi'nde 1070 m yükseklikteki Sülük Gölü ve 820 metre yükseklikteki Sünnet Gölü'nde tespit edilmiştir (Yıldız vd., 2008). Ayrıca daha düşük 
rakımlarda bulunan Sazlıgöl (Balık vd., 2001), Terkos Gölü'nde (Çamur-Elipek, 2003), Göller Bölgesi sucul ekosistemlerinde (Yıldız ve Balık, 2005) ve Yuvarlakçay'da (Yıldız vd., 2007b) tespit edilmiştir.

Aulodrilus türleri aseksüel olarak ürerler ve çoğunlukla mezotrofik ya da yabani otlarla dolu istasyonlarda bulunurlar. Tüp içinde sedimente yapışık olarak bulunabilirler. Aulodrilus pluriseta, kozmopolittir, geniş varyasyon gösteren habitatlarda bulunur, fakat çamurlu substratlı zenginleşmiş çevrelerde daha boldur. Tatı su formudur. Göller, nehirler, kanallar ve havuzlarda yaygındırlar (Yıldız ve Balık, 2005). Bazı oligoket türleri çürümüş doğal organik maddenin olduğu suları tercih eder gibi, ayrıca kağıt hamuru fabrikası atıklarından kaynaklanan organik atıkların olduğu sularda bile yaşarlar. $A$. pluriseta bunlardan birisidir (Särkkä, 1987). Oligotrofik şartların indikatörüdür (Milbrink, 1980). Bu tür ülkemizin değişik bölgelerinde yapılan çalışmalarda tespit edilmiştir (Arslan ve Şahin 2003; Ötürk ve Arslan, 2003; Çamur-Elipek, 2003; Balık vd., 2004; Yıldız ve Balık, 2005; Yıldız vd., 2007a; Yıldız vd., 2008; Yıldız vd., 2010b; Taş vd., 2011; Yıldız vd., 2012).

Çalışmada tespit edilen ikinci ordo Lumbriculida ordosudur ve Lumbriculidae familyasından tek türle temsil edilmiştir. Bu familya, kuzey Ilıman zonun termofob familyasıdır. Esas olarak dereler, kaynaklar ve soğuk göllerde populasyon oluştururlar (Timm, 1980). Yaygın Iıman zon türleri olan bu familya üyeleri, kaynak dereleri ve su sıcaklığııın $+4^{\circ} \mathrm{C}$ 'nin üstüne çıkmadığı kuzey göllerinin diplerinde bile başarılı olarak populasyon oluşturabilirler.

Lumbriculus variegatus türünün Kuzey Yarımküre, Güney Afrika, Avustralya ve Yeni Zelanda'dan dağılımı verilmiştir. Holarktik bölgede bulunan iki lumbriculidten biridir. Geniş ekolojik valanslıdır. Daha sıcak yüzey sularında geniş yayılım gösterir. Havuzlar, göl kenarları ve derelerde yaygındır, buraların littoral kısımlarında bulunurlar. Ayrıca çoğu Oligoket için uygun olmayan bataklık sular ve efemerel havuzlarda dahi bulunur (Timm, 1970). Hatta balık yetiştirilen kanallarda, vejetasyonlu ve bol yosunlu yerlerde büyük populasyonlar oluş̧ururlar (Yıldız ve Balık, 2005). Martinez vd. (2006), bu türün çevresel şartların hızlı değiştiği ve predator ataklarının yaygın olabileceği sığ havuzlarda yaşadığını bildirmişlerdir. Bu türün ülkemizdeki dağılış alanları yapılan bir çok çalışma ile saptanmıştır (Geldiay ve Tareen, 1972; Balık vd; 2000; Arslan ve Şahin., 2003; Duran vd., 2003; Balık vd., 2004; Yıldız ve Balık, 2005; Arslan, 2006a; Arslan, 2006b; Yıldız vd., 2007a; Yıldız vd., 2007b; Y.ldız vd., 2009).

Çalışmada Enchytraeidae familyasına da rastlanmıştır. Bu familya da Kuzey Yarımküre kökenlidir. Aynı Lumbriculidae familyası gibi tek türle temsil edilmiştir. Enchytraeid'ler, diğer oligoket familyalarına göre daha fazla habitat tiplerinde yaygındırlar. Polar bölgelerden (Arktik ve Antarktik) tropiklere, göllerin diplerinden nehirlere ve okyanusların diplerine, kalıcı buzların olduğu ya da karların olduğu ortamlarda ve buzlu karalarda, lağım sularının aktığı yataklarda, temiz deniz kumlarında, su ile ağırlaşmış toprakta ve tüm toprak tiplerinde bulunabilirler. Avrupa'da toprak kalitesini izlemede biyolojik belirleyici olarak kullanılmaktadırlar (Yıldız ve Balık, 2005).

Cognettia türleri düşük $\mathrm{pH}$ değerlerine karşı toleransııdır; şöyleki, düşük $\mathrm{pH}$ değerleri diğer bazı türlerin fizyolojik reaksiyonların oranını azaltıcı rol oynar (Standen, 1982). Cognettia glandulosa holarktik dağılıma sahiptir. Toprakta ve tatlı sularda kıyilarda bulunur (Timm ve Veldhuijzen Van Zanten, 2002). Islak toprakları tercih eder (Healy ve Bolger, 1984). Ülkemizde bu türe Tunca Nehri (Kırgız vd., 2005) ve Kaçkar Dağları'ndaki buzul göllerinde rastlanmıştır (Yıldı vd., 2010a; YIldız vd., 2012).

Çalışmada tespit edilen Tubificida ordosuna bağlı diğer bir familya Naididae'dir. 2 genus içinde 2 tür ile temsil edilmiştir.

Naidid'ler çok çeşitli sucul habitatlarda yaşarlar, fakat özellikle taşlı substratlı nehirlerin bentik faunasını önemli bir kısmını oluştururlar. Bu familyanın üyelerinin çoğu kozmopolittir ve dünyanın her yerinde bulunur (Wetzel vd., 2000) ve çok geniş çevresel şartlara adapte olabilirler (Brinkhurst ve Jamieson, 1971). Genelde bakteriler ve alglerle, diğer epifitik materyallerle beslenirler (Brinkhurst ve Gelder, 1991). Bazıları predatör (Chaetogaster spp.), bazıları molluskların (gastropod) parazitidir. Naidid türlerinin dağılım ve bolluklarının değerlendirilmesindeki ana faktörler, substratumun doğası ve vejetasyon çeşitliliğinin varlığıdır. Naidid'ler genelde, aseksüel üreme ve gelişimin yüksek temperatürle teşvik edildiği, besinin çok bol olduğu yaz aylarında daha boldur (Learner vd., 1978). Çoğu kozmopolittir ve tüm dünyada bulunur. Kültürleri de yapılabilen ekonomik bir familyadır.

Nais elinguis, kozmopolit bir türdür. Nais variabilis ve Nais communis türleri gibi en yaygın Avrupa türleri arasında yer alır ve yine onlar gibi taşlı substratumlu ve organik madde bakımından zengin nehirlerde bolluğu artar. Sık sık acısularda, acısularda olduğu kadar tatılı sularda (esas olarak kaynaklarda) bulunur. Geniş varyetedeki çevresel şartlarda (soğuk, hızlı akan nehirlerden, çamurlu-kötü kokulu, zayıf oksijenli alanlar) bulunabilir (Timm ve Veldhuijzen Van Zanten, 2002). Ayrıca sık sık salinitesi \%o 23'lerdeki acısulara bile alışabilir. Lateral hareketlerle yüzer. Kumlu substratlarda kum parçacıklarını süzerek (bakteriyel film tabakasında) beslenir. Sıcak sezonlarda aktif olarak çoğalır (Mayıs-Ekim). Brinkhurst (1971), bu türün organik kirliliğe dayanıklı tür olarak bilindiğini belirtmiştir. Eğer organik kirliliğin olduğu yerde bulunuyorsa, oksijen eksikliğinin olmadığı durumlarda bulunabilir (Paoletti ve Sambugar, 1984). Soğuk kaynak sularının karakteristik bir türüdür (Timm vd., 2001). Brinkhurst (1962)'ye göre ayrica kirlenmiş derelerde de çok bol bulunabilir (Timm vd., 2001). Ayrıca çok geniş varyetedeki yaşama ortamlarında bulunabilen bir türdür. Ülkemizde bu türün dağıımını gösteren bir çok çalışma mevcuttur (Moubayed vd., 1987; Arslan ve Şahin, 2003; Balık vd., 2004; Arslan ve Şahin, 2004; Yıldız ve Balık, 2005; Arslan ve Şahin 2006; Arslan vd., 2007a; Arslan vd., 2007b; Yıldız vd., 2007b; Yıldız vd., 2008; Yıldız vd., 2010b). 
Sonuç olarak, bu göllerde yapılan çalışmalarda elde edilen türler, ülkemizdeki diğer dağ ve alpin göllerdeki dağlarda tespit edilen türlerle benzerlik göstermektedir. Bu çalışmada alpin karakterde olan tek gölümüz Kartal Gölü'dür. Kartal Gölü giriş ve çıkış sularından elde edilen türler Kaçkar Dağları'ndaki buzul göllerden tespit edilen soğuk dağ gölü karakterine sahip oligoket türleridir. Oligotrofik ortamlara uyum sağlamışlardır (Yıldız vd., 2012).

\section{KAYNAKÇA}

Arslan, N. \& Şahin, Y. (2003). Two new records of Aulodrilus Bretscher, 1899 (Oligochaeta, Tubificidae) for the Turkish fauna. Turkish Journal of Zoology, 27: 275-280.

Arslan, N. \& Şahin, Y. (2004). First Records of Some Naididae (Oligochaeta) Species for Turkey. Turkish Journal of Zoology, 28: 7-18.

Arslan, N. (2006a). Records of Aphanoneura and aquatic Oligochaetes from Turkey," Fresenius Environmental Bulletin, 15 (4): 249-254.

Arslan, N. (2006b). Littoral fauna of Oligochaeta (Annelida) of Lake Eğirdir (Isparta), Turkey. Ege Journal of Fisheries and Aquatic Sciences, 23 (34): 315-319.

Arslan, N. \& Şahin, Y. (2006). A preliminary study on the identification of the littoral oligochaete (Annelida) fauna of Lake Kovada, a national park in Turkey. Turkish Journal of Zoology, 30: 67-72.

Arslan, N., İlhan, S., Şahin, Y., Filik, C., Yılmaz, V. \& Öntürk, T. (2007a) Diversity of Invertebrate Fauna in Littoral of Shallow Musaözü Dam Lake in Comparison with Environmental Parameters. The Journal of Applied Biological Sciences, 1(3): 67-75

Arslan, N., Timm, T. \& Erséus, C. (2007b). "The Aquatic Oligochaeta (Annelida) of Balıkdamı Wetland in Turkey, with Descriptions of Two New Species Phallodrilinae. Biologia, 62/3: 323-334.

Balık, S., Ustaoğlu, M. R., Taşdemir, A.\& Yıldız, S. (2000). The Benthic Fauna of Lake Işıkı (Çivril-Denizli) (in Turkish). In: XV National Biology Congress, Volume I, Ankara, pp. 210-216.

Balık, S., Ustaoglu, M. R., Yıldız, S. \& Tasdemir, A. (2001). The Benthic Fauna (Oligochaeta-Chironomidae) of Sazlıgöl (Menemen-İzmir) (in Turkish). XI. National Fisheries Symposium, 1: 198-205, Hatay.

Balık, S., Ustaoğlu, M.R. \& Özbek, M. (2003). The Mollusca Fauna of Some Lakes Located on Mounts Taurus (South Anatolia) (in Turkish with English abstract). Ege Journal of Fisheries and Aquatic Sciences, 20: 351-355.

Balık, S., Ustaoglu, M. R. \& Yıldız, S. (2004). Oligochaeta and Aphanoneura (Annelida) Fauna of Gediz Delta (Menemen-IZMIR). Turkish Journal of Zoology, 28 (3): 183-197.

Brinkhurst, R. O. (1971). A Guide for the Identification of British Aquatic Oligochaeta, Freshwater Bio. Ass. Sci. Pub, No:22, 55p.

Brinkhurst, R.O. (1974). The Benthos of Lakes. Mac Millan Press Ltd. London, $190 \mathrm{p}$.

Brinkhurst, R. O. \& Jamieson, B.G.M. (1971). Aquatic Oligochaeta of the World, Univ. of Toronto, $860 p$.

Brinkhurst, R. O. \& Gelder, R. S. (1991). Annelida: Oligochaeta and Branchiobdellidae, In: Ecology and Classification of North American Freshwater Invertebrates. Academic Press, Inc, pp: 400-435.

Çamur-Elipek, B. (2003). The dynamics of Benthic macroinvertebrates in a mesotrophic lake: Terkos, Turkey. Acta biologica iugoslavica - serija D: Ekologija, 38(1-2): 31-40.

Dağdelen, H. (2016). The dance of light with the water SAKLIGÖL. Yeni Asır 02.03.2016, (http://www.yeniasir.com.tr/sarmasik/2013/01/13/isigin-suyladansi-sakligol) (in Turkish).

Dumnicka, E. \& Galas, J. (2002). Factors affecting the distribution of Oligochaeta in small high mountain ponds (Tatra Mts, Poland). Archiv für Hydrobiologie, 156(1): 121-133.
Ayrıca tespit edilen türler bu bölgedeki göller için yeni kayıt niteliğindedir.

\section{TEŞEKKÜR}

Bu çalışmayı finansal açıdan destekleyen Ege Üniversitesi Bilimsel Araşıtıma Projeleri Şube Müdürlüğüne (BAP Proje No: 2009/SÜF/002) teşekkür ederiz.

Duran, M., Tüzen, M. \& Kayım, M. (2003) Exploration on biological richness and water quality of Stream Kelkit, Tokat-Turkey. Fresenius Environmental Bulletin, 12(4): 368-375.

Fittkau, E. \& Reiss, F., (1986). Chironomus. mitteilunger aus der chironomidenkunde-Plön. München.

Geldiay, R. \& Tareen, I.U. (1972). Bottom fauna of Karagöl lake. Scientific reports of the Faculty of Science, Ege University, No:137, 15 pp.

Genç, F (2014). With the nature beauty, Bozkurt (in Turkish). Denizli Güncel. Retrieved from: http://www.denizliguncel.com/dogal-guzellikleriylebozkurt-makale,12.html (02.03.2016).

Healy, B. \& Bolger, T. (1984). The occurrence of species of semi-aquatic Enchytraeidae (Oligochaeta) in Ireland. Hydrobiologia 115: 159-170. doi: $10.1007 / B F 00027911$

Kırgız, T., Çamur-Elipek, B. \& Arslan, N. (2005). Preliminary study of Enchytraeidae (Oligochaeta) in the Tunca River (Thrace, Turkey Proceedings of the Estonian Academy of Sciences: Biology, Ecology, 54 (4): 310-314

Learner, M.A., Lochhead, G. \& Hughes, B.D. (1978). A review of the Biology of British Naididae (Oligochaeta) with Emphasis on the the Lotic Environment. Freshwater Biology, 8: 357-375. doi: 10.1111/j.1365-2427.1978.tb01457.x

Mani, M. S. (1968). Ecology and Biogeography of High Altitude Insects. Dr. W. Junk N.V. Publishers, the Hague, 527p. doi:10.1007/978-94-017-1339-9

Marchese, M. R. (1987). The ecology of some benthic oligochaeta from the parana River, Argentina. Hydrobiologia 155: 209-214. doi:10.1007/BF00025653

Martinez, V. G., Prashant, K. R. \& Zoran, M. J. (2006). Asexual reproduction and segmental regeneration, but not morphallaxis, are inhibited by boric acid in Lumbriculus variegatus (Annelida: Clitellata: Lumbriculidae). In: Aquatic Oligochaete Biology IX P.F.M. Verdonschot, H. Wang, A. Pinder, R. Nijboer (Eds). Hydrobiologia, 564: 73-86.

Milbrink, G. (1980). Oligochaete communities in pollution biology. The European situation with special reference to lakes in Scandinavia. In: Aquatic Oligochaete Biology. Brinkhurst, R. O. and Cook, D.G. (ed). Plenum Publishing Corporation, N.Y, pp: 433-455. doi:10.1007/978-1-4613-3048-6_22

Moubayed, Z., Giani, N. \& Martinez-Ansemil, E. (1987). Distribution of Aquatic Oligochaeta and Aphanoneura in the Near East. In Beihefte zum Tuibinger Atlas des Vorderen Orients, Ser. A, L. Reichert Pub., Wiesbaden 28: 8090.

Nielsen, C.O. \& Christensen, B. (1959). The Enchytraeidae Critical Revision and Taxonomy of European Species, (Studies on Enchytreidae VII). Naturhistorisk Museum-Aarhus,160p.

Öntürk, T. \& Arslan, N. (2003). A preliminary study for the determinationon the Oligochaeta and Chironomidae fauna of Gümüş Stream (MardinKızltepe) (in Turkish with English abstract). pp. 82-86. In: Oral Presentations, Book of Fisheries and Aquatic Science Symposium

Paoletti, A. \& Sambugar, B. (1984). Oligochaeta of the middle Po River (Italy): principal component analysis of the benthic data. Hydrobiologia, 115: 145152. doi:10.1007/BF00027909 
Sarı, H. M., Ustaoğlu, M. R., Illhan, A. \& Özbek, M., (2015). The Morphometric Characteristics of Lakes of Mounts of Kaçkar ve Soğanlı (Turkey) (in Turkish with English abstract). Ege Journal of Fisheries and Aquatic Sciences, 32 (1): 31-36. doi: 10.12714/egejfas.2015.32.1.05

Särkkä, J. (1987). The occurrence of oligochaetes in lake chains receiving pulp mill waste and their relation to eutrophication on the trophic scale. Hydrobiologia, 155: 259-266. doi:10.1007/BF00025658

Standen, V. (1982). Associations of Enchytraeidae (Oligochaeta) in Experimentally Fertilized Grasslands. The Journal of Animal Ecology, 51 (2): 501-522. doi:10.2307/3980

Sahin, Y. (1991). The Chironomidae Potamofauna of Turkey (in Turkish with English abstract). TÜBITAK Project no: TBAG-869.

Taş, M., Çamur Elipek, B., Kırgız, Timur., Arslan, N. \& Yıldız, S. (2011). The Aquatic and Semi-Aquatic Oligochaeta Fauna of Turkish Thrace Region. Journal of FisheriesSciences.com, 6(1): 26-31.

Taşdemir, A., Yıldız, S., Topkara, E.T., Özbek, M., Ustaoğlu, M.R. \& Balık, S. (2004a). The Benthic Fauna of Lake Yayla (Buldan-Denizli) (in Turkish with English abstract). Turkish Journal of Aquatic Life, 2: 182-190.

Taşdemir, A., Ustaoğlu, M. R. \& Balık, S. (2004b). The Diptera (Insecta) Fauna of Ikizgöl (Bornova, İzmir, Turkey) (in Turkish with English abstract). Ege Jornal of Fisheries and Aquatic Sciences, 21(3-4): 263-265.

Taşdemir, A., Ustaoğlu, M.R., Balık, S. \& Sarı, H.M. (2010). A Study of Chironomidae (Diptera-Insecta) Fauna of High Mountain Lakes on The Eastern Black Sea Range (in Turkish with English abstract). 4. National Limnology Symposium, 4-6 August, Bolu.

Thienemann, A. (1954). Chironomus, Leben, Verbreitungen und Wirtschaftliche Bedeutung der Chironomiden. Binnengewasser. 2: 1-834

Timm, T. (1970). On The Fauna of Estonian Oligochaeta. Pedobiologia, Bd. 10: $52-78$.

Timm, T. (1980). Distribution of Aquatic Oligochaetes. In: Aquatic Oligochaete Biology. Brinkhurst, R. O. and Cook, D.G. (ed). Plenum Publishing Corporation, N.Y, pp: 55-77. doi:10.1007/978-1-4613-3048-6_6

Timm, T., Seire, A. \& Pall, P. (2001). Half a century of oligochaeta research in estonian running waters. Hydrobiologia, 463, 223-234. doi:10.1023/A:1013176229631

Timm, T. \& Veldhuijzen van Zanten, H. H., (2002). Freshwater Oligochaeta of North-West Europe. World Biodiversity Database, CD-ROM Series. Expert Center for Taxonomic Identification, University of Amsterdam.

Timm, T. (2009). A guide to the freshwater Oligochaeta and Polychaeta of Northern and Central Europe. Lauterbornia, D-86424 Dinkelscherben. 66:1-235.

Topkara, E. T., Taşdemir, A., Yıldız, S., Ustaoğlu, M. R. \& Balık, S. (2009) Contributions to The Aquatic Insect (Insecta) Fauna of The Taurus Mountain Range (in Turkish with English abstract). Journal of FisheriesSciences.com, 3(1): 10-17.

Topkara, E.T. \& Ustaoğlu, M.R. (2015). A study on the aquatic Coleoptera and aquatic semiaquatic Heteroptera (Insecta) fauna of Lake Kartal (Denizli) and ecological notes. Ege Journal of Fisheries and Aquatic Sciences, 32(1): 45-50. doi: 10.12714/egejfas.2015.32.1.07

Ustaoğlu, M.R. (1980). Investigation On The Benthic Fauna (Oligochaeta, Chaoboridae, Chironomidae) of Lake Karagöl (Yamanlar-Izmir) (in Turkish). TÜBITAK VII. Science Congress (Biology Section) 6-10 October 1980, Aydın: 331-334.
Ustaoğlu, M. R., Balık, S. \& Özbek, M. (2004). Contributions to the Knowledge of Malacostraca (Crustacea) Fauna of the Taurus Mountains District (Southern Anatolia). Turkish Journal of Zoology, 28: 91-94.

Ustaoğlu, M. R., Balık, S., Özdemir Mis, D. \& Aygen, C. (2005). The Zooplankton of Some Lakes in the Taurus Range (Turkey). Zoology in the Middle East, 34: 101-108. doi: 10.1080/09397140.2005.10638089

Ustaoğlu, M.R., Balık, S., Sarı, H. M., Mis, D., Aygen, C., Özbek, M., Illhan, A., Taşdemir, A., Y.ldız, S. \& Topkara, E. T. (2008). The Fauna of the Glacier Lakes and Streams on Uludağ (Bursa) (in Turkish with English abstract). Ege Journal of Fisheries and Aquatic Sciences 25(4): 295-299.

Wetzel, M. J., Kathman, R. D., Fend, S.V. \& Coates, K. A. (2000). Taxonomy, Systematics and Ecology of Freshwater Oligochaeta. Workbook Prepared for North American Benthological Society Technical Information Workshop, 48th Annual Meeting, Keystone Resort, CO, 120 p.+ app.

Yıldız, S. \& Balık, S. (2005). The Oligochaeta (Annelida) Fauna of the Inland Waters in the Lake District (Turkey), Ege Journal of Fisheries and Aquatic Sciences, 22(1-2): 165-172.

Yıldız, S., Taşdemir, A., Özbek, M., Balık, S. \& Ustaoğlu, M.R., (2005). Macrobenthic Invertebrate Fauna of Lake Eğrigöl (Gündoğmuş-Antalya). Turkish Journal of Zoology, 29: 275-282.

Yıldız, S., Ustaoğlu, M.R. \& Balık, S. (2007a). Contributions To The Knowledge Of Oligochaeta (Annelida) Fauna of Some Mountain Lakes on the Taurus Range (Turkey). Turkish Journal of Zoology, 31: 249-254.

Yıldız, S., Balık, S. \& Ustaoğlu, M. R. (2007b). The Oligochaeta (Annelida) Fauna of Yuvarlak Stream (Köycegiz-Turkey). Turkish Journal of Fisheries and Aquatic Sciences, 7(1): 1-6.

Yıldız, S., Ustaoğlu, M. R., Balık, S. \& Sarı, H. M. (2008). Contributions to the Knowledge of Oligochaeta (Annelida) Fauna of Some Lakes in the West Black Sea Region (Turkey). Journal of the Black Sea-Mediterranean Environment. 14(3): 193-204.

Yıldız, S., Ustaoğlu, M.R. \& Balık, S. (2009). Contributions to an Eutrophic Mountain Lake: Oligochaetes (Annelida) of İizgöl (Bornova-Izmir) (in Turkish). XV. National Fisheries Symposium "Aquaculture with the Ecosystem Approach", 374.

Yıldız, S., Ustaoğlu, M. R. \& Balık, S. (2010a). Littoral Oligochaeta (Lumbriculidae and Enchytraeidae) communities of some mountain lakes on Eastern Black Sea range (Turkey). Zoology in the Middle East, Supplementum 2, Advances in Earthworm Taxonomy, 151-160.

Yıldız, S., Özbek, M., Taşdemir, A. \& Balık, S. (2010b). Identification of Predominant Environmental Factors Structuring Benthic Macro Invertebrate Communities: A Case Study in The Küçük Menderes Coastal Wetland (Turkey). Fresenius Environmental Bulletin, 19(1): 30-36.

Yıldız, S., Özbek, M., Ustaoğlu, M.R. \& Sömek, H. (2012). Distribution of Aquatic Oligochaetes (Annelida, Clitellata) of high elevation lakes in the Eastern Black Sea Range of Turkey. Turkish Journal of Zoology, 36 (1): 59-74. doi:10.3906/zoo-1002-39

Yıldız, S., Özbek, M., Taşdemir, A. \& Topkara, E. T. (2015). Assessment of a Shallow Montane Lentic Ecosystem (Lake Golcuk, Izmir, Turkey) Using Benthic Community Diversity. Ekoloji, 24: 1-13. doi: 10.5053/ekoloji.2015.34 